\title{
The Reverse Logistics Issues in the Recall Process as an Improvement Factor in the Automotive Segment
}

\author{
Getulio K. Akabane ${ }^{1, *}$, Fernando José Bussola1, Antonio César Galhardi', \\ José Martino Neto', Takeshy Tachizawa² \\ ${ }^{1}$ State Technology Education Center (CPS) Master Program, Sao Paulo-Brazil \\ ${ }^{2}$ Campo Limpo Paulista University Center Master Program (UNIFACCAMP), São Paulo-Brazil
}

Copyright $C 2018$ by authors, all rights reserved. Authors agree that this article remains permanently open access under the terms of the Creative Commons Attribution License 4.0 International License

\begin{abstract}
The present study seeks to identify the processes of reverse logistics as a differential factor in the improvement of the product and / or process, through the case study in the reverse logistics of a recall of a large proportion of airbags for the purpose of performing the experience report through a single case study. The company in question has more than 200 points of service distributed throughout the great Brazilian territory, and is segmented according to Figure 3 below into 5 (five) large regions, according to the distribution and regions served by 5 loads. Outbound logistics follows the full flow of the supply chain, that is, from the origin (factory) to the dealers (delivery points), through points of consolidation of cargo due to long distance and fractional distribution (low volume). In fact, a "recall" process, where there is a whole commitment to image, end customer and understand the real root cause of the problem, reverse logistics becomes a differentiated process in the preservation of industrial operation. It is an innovative and unique initiative within the automotive segment, where the safety and reliability factor has a primary emphasis on corporate image at the global level. Reverse logistics had a decisive and important role in the recall process where procedures and flows are designed exclusively to meet this specific demand. The result leads to important reflections in which the cost factor has implications on the company's results in the short term. However, over time the qualitative question is the element that ensures the image and the fundamental institutional continuity that can differentiate in the long term. This paper concludes with the discussion of theoretical and practical contributions, limitations, and avenues for future research.
\end{abstract}

Keywords Reverse Logistics, Recycling, Point of Consumption, Product Improvement

\section{Introduction and Literature Review}

Manufacturers in the automotive segment always seek the continuous improvement of products and processes in obtaining the competitive advantage in its segment of operation.

The inclusion of the evaluation link of the products returned by the reverse chain allows the identification of the possible root cause of the problem detected in the field and the adequate use of the analysis tools, allowing continuous improvements and improvements, both in the products and in the manufacturing processes.

The present study aims to identify the processes of reverse logistics as a differential factor in the improvement of the product and / or process, through the case study in the reverse logistics of a recall of a large proportion of airbags.

\section{Reverse Logistic}

Leite (2003) understands Reverse Logistics as the area of Business Logistics that plans, operates and controls the flow, and the corresponding logistic information according to its nature, characteristic and destination, which are: post-sale or post-consumer ode. In this way, economic, financial, environmental, legal, logistical value, reputation and image can be added, among others.

The Post-Sale link involves the processes of physical and logical flow of the goods and services of discards and of discrepancies at the point of consumption. These items may have recycle, refurbishment or repair destinations or as refuse and may return to stock directly or some other intermediate or definitive process.

In the Post-Consumer link discarded in final consumption by society in general. Usually refers to end of life products due to obsolescence where it requires adequate under the law of shared responsibility.

After-sales products return through direct distribution chain itself, having in general as origin of return one of chain links or final consumer itself and having as product manufacturer usually destination. Figure 1 below details the various possibilities of return of this category of goods. 


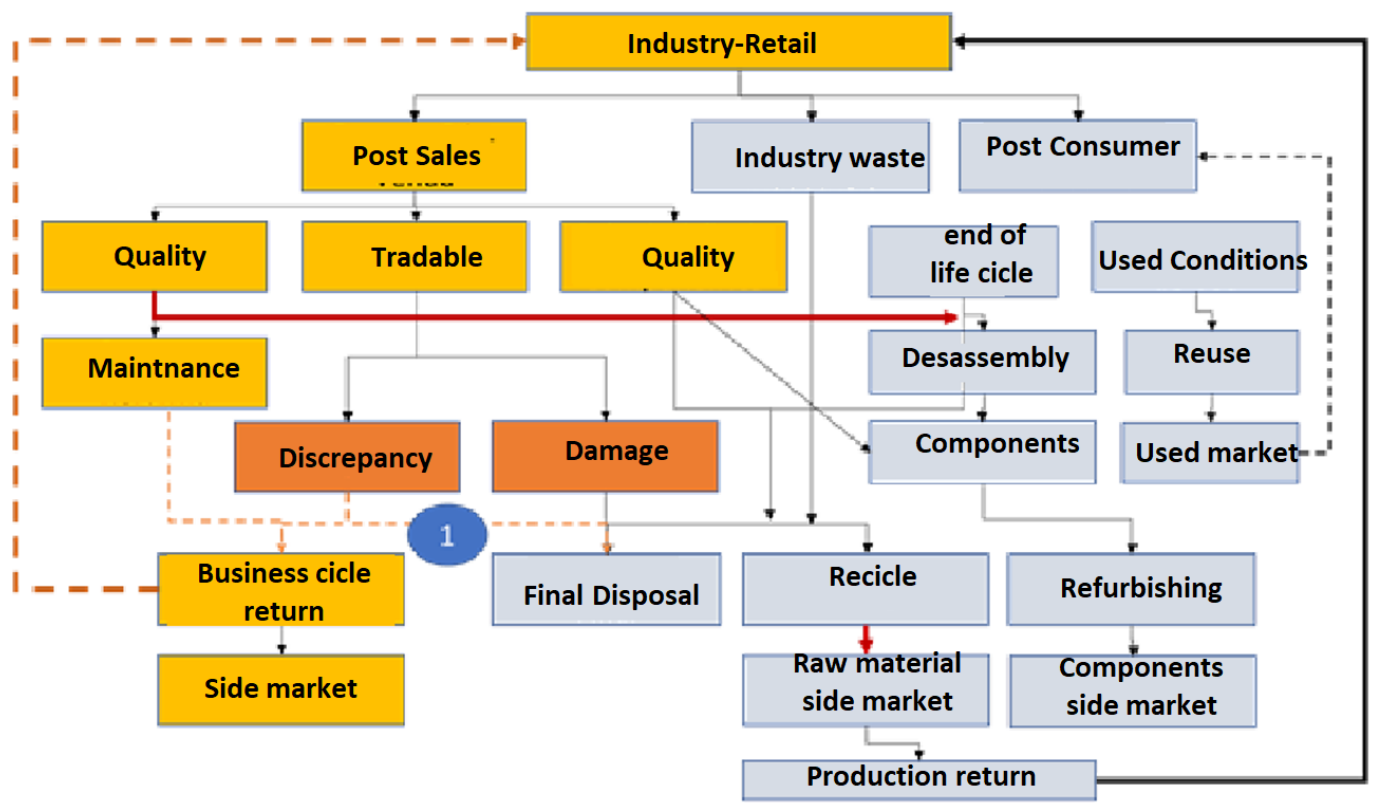

Source: Adapted from Leite (2003).

Figure 1. Reverse Post-Sales Logistics

Even shows the steps that make up where Reverse Post-Sales Logistics are contextualized in the "Warranty/Quality", "Commercial" and "Component Replacement" classifications.

In this way the "Warranty/Quality" refers to products with manufacturing defects or malfunctions and breakdowns in the product or in the packaging. These products are analyzed for subsequent repairs or adjustments to return to the primary or secondary market with corresponding commercial value.

In the "Commercial" classification there is a category of "Breakdowns" that arise from transportation failures or similar situation and "Discrepancy", characterized by return due to shipping discrepancies, high level of inventory in the distribution channel, consignment goods, seasonal settlement, "Recalls", among others that can be returned to the business cycle through analyzes and verifications to be redistributed through other sales channels or discarded.

On the other hand, the classification "Replacement of Components" falls into the cases where there is substitution of components of durable and semi-durable goods derived from maintenance and repairs throughout their useful life, considered remanufactured, being able to return to the primary or secondary market or, after analysis are sent to the recycling or to a final destination, in the impossibility of reuse.

Petersen \& Kumar (2009) define the return of products as an imminent part of the exchange between companies and final consumers. In fact, Supply Chain entities encourage and promote a liberal product return policy as a form of competitive advantage to gain consumer satisfaction and loyalty (COHEN \& WHANG, 1997).
The return of products can occur due to 1) return to the end of the life cycle of the product where products return due to environmental legislation (eg Solid Waste Law), 2) return of the product after the end of the customer's use , where the products return after their use for later reconditioning or use of parts to take advantage of the remaining residual economic value (GUIDE \& WASSENHOVE, 2001) and 3) commercial return, where the return of the product occurs due to improper performance or presentation of some risk of security.

In the first two types, the products are "pulled" and therefore may have less instability regarding product quality (PRAHINSKI \& KOCABASOGLU, 2006). On the other hand, in the commercial returns, the products are "pushed", being able to present greater instability in this question.

According to Blackburn et al. (2004), the return of the product or its process follows three sequential steps: product reacquisition, reverse logistics and inspection / disposal. Product repurchase involves getting back the end customer's product. Reverse logistics involves "transporting the products to a particular location for inspection, sorting and disposal" which involves "evaluating the conditions for return".

Caldwell (1999), LEITE (2003, p.216-218), ROGERS e TIBBEN- LEMBKE, (1999, p.78-86), presented the returned products main destinations without consumption as a summary of figure 1 listed below:

1. Resale in the primary market - Returned products due to stock adjustments in the direct distribution channels usually have general conditions of being sent back to the primary market, ie the original market, with the manufacturer's logo and through redistribution; 
2. Repairs and refurbishing - In the case of requirements of this nature, return products will be necessary repairs and may be marketed on the primary often on the secondary market;

3. Dismantling - The dismantling destination occurs when returned with no operating conditions even for the design utility and exists value of use in its components.

This operation is usually carried out by companies under these conditions and components will be sent to secondary parts market or subassemblies or before passing by remanufacturing process. The products saved from the accidents and designated to the secondary market are examples of this reverse channel category;

4. Remanufacturing - The remanufacturing process will take place when defective components find from the returned goods and must redone to be sent to the secondary market. Many large companies use the component disassembly and review system in order to supply the spare parts market by recovering important values;

5. Industrial recycling - Subassemblies or parts of the structure are marketed through specialized companies to be recycled;

6. Final provision - There being no other solution to add value of any kind of solutions are returned to landfills or to the incineration process depending on the peculiarities of each country or region; and

7. Donation - This is usually associated with degree of obsolescence. This is a very common case in the computer sector that has very short useful average but which are of interest or required in the particular country.

Regardless of the supply chain link in the consumer goods industry that owns the brand, a defective product is usually returned by the customer to the point where it was originally purchased, in many cases the retailer (PETERSEN \& KUMAR, 2009). Thus, the first step in the return process, the product repurchase, is carried out by the retailers.

If the returned product is a private label owned by the reseller, it can also perform the next two steps, ie reverse logistics and inspection / disposal. In addition, since private labels are sold exclusively at the reseller's points of sale (JOHNSON, 2001), it can easily centralize and consolidate the number of returned products, obtaining a sample large enough for detailed quality inspection. If the returned product inspection shows a high potential for safety risk, the reseller can initiate product recall.

However, if the returned product is the responsibility of the distributor or the manufacturer, the reverse logistics involves the transportation of the product to this responsible person, who from then on can then carry out the inspection. The reverse logistics step between rebuilding the product at the dealer and inspection at the facility managed by the distributor or manufacturer delays the entire process of return analysis. This occurs when the re-acquisition processes are decentralized also because each reseller has its own internal process and relationship with the distributor / manufacturer (HORA ET AL., 2011).
In addition to the delay in the return process of the returned product to the responsible links in the supply chain, the longer flows that have more distance between distributor / manufacturer and end customer are more susceptible to problems generated by information that does not arrive correctly and / or do not arrive in acceptable deadlines, which can bring more damages to the companies and for that reason it is pointed out by Hora et al. (2011) as an important point of attention for the managers of the companies responsible for the brand of the products.

\section{Recall}

In a more specific analysis, for Hora et. al (2011) the recall of a product aims at the withdrawal of a product, a lot or a part of the product from the market in which it is or has been sold. A typical recall process encompasses an official advertisement explaining the reasons and the contour action for the consumer.

Recall processing refers to a part of reverse logistics because it requires a logistics plan to get the product back and then discard, repair or refund as purchase price. (JAYARAMAN ET AL., 2003).

This process is associated with considerable costs to companies, both current and future, including inconvenience to consumers, declining financial performance and even loss of life (SHAH, 2011). In addition to corporate costs, companies face costs of external failures, both direct and indirect, arising from product recalls. The direct costs include the costs of managing the reverse logistics of products, of elimination and restitution, of legal costs and of liability for contingencies (BERMAN, 1999; DAWAR AND PILLUTLA, 2000; RUPP, 2004; TANG, 2008). The indirect costs may eventually be higher than the direct costs, we may include the loss of the brand image with declining market value (Smith \&.

Recalling a defective product to the market represents a manufacturer's failure to provide the appropriate level of quality for the product's life cycle and this can also mean serious problems throughout the chain. Possible causes of defects include design flaws, production errors, material defects, functional defects, packaging errors, and software failures. (THIRUMALAI \& SINHA, 2011).

It is up to the company responsible for the manufactured or imported product, to initiate an investigation to detect the root cause and treat it definitively, so that it is possible to take action to recover the damages caused.

\section{Research}

\section{Overview of the Automotive Industry in Brazil}

The automotive sector is one of the great players of the national and world economy and feeds the innovation in large scale, due to the high competitiveness of the sector and its pre-disposition in the search of the continuous improvement, either to improve the product for the client or 
to increase its profitability.

According to ANFAVEA (2017b), in Brazil the automotive sector has 67 industrial units, distributed throughout the national territory and currently employs more than 121 thousand direct employees and approximately 1.3 million jobs throughout the production chain. By 2017, a national production of 2.2 million vehicles is estimated, with a growth prospect for the coming years, as shown in Chart 1 .

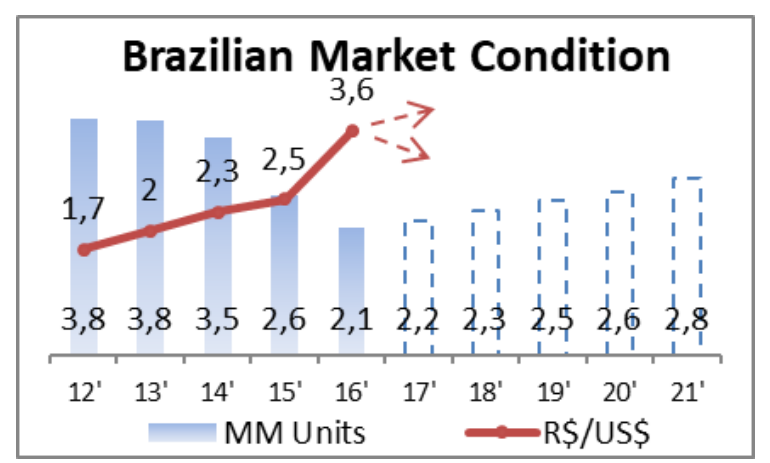

Source: ANFAVEA (2017a).

Chart 1. Number of vehicles produced in Brazil and Dollar variation in relation to the Real.

Also, according to ANFAVEA (2017b), 4393 concessionaires are distributed in the 5 regions for the commercialization and, possibly, provision of services for automobiles, as shown in Chart 2.

The dealerships make up a very important link within the Automotive Chain. They are one of the main channels of direct relationship with the final consumer and are also responsible for after sales services such as maintenance, repair, service to recalls and others.

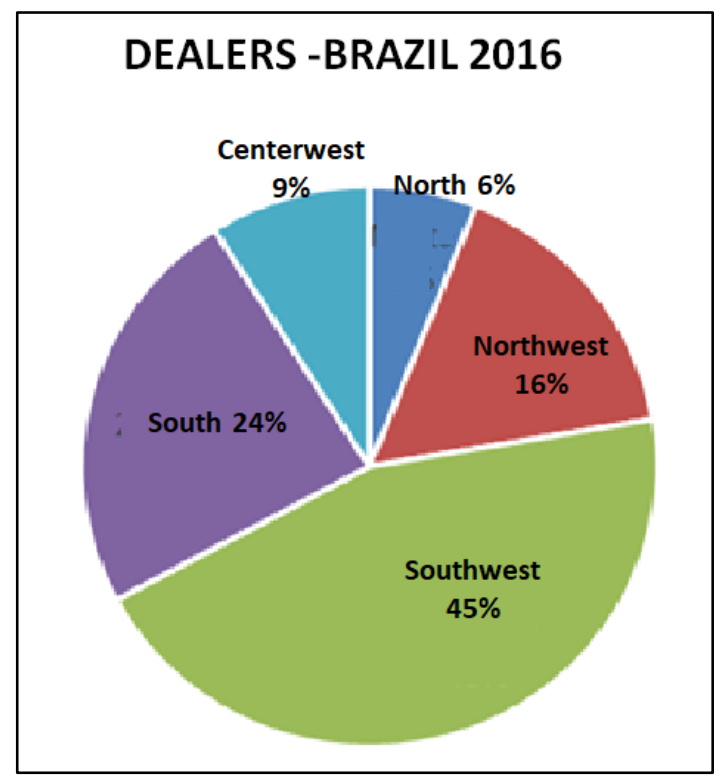

Souce: ANFAVEA (2017a).

Chart 2. Auto vehicle dealers by region in Brazil.

\section{Research Method}

The purpose of the present study is to report the experience of airbag recall using a single case study. The object of study is the recall of airbaigs from an automotive manufacturer, which used reverse logistics as a competitive differential in the implementation of continuous improvement in its processes and products through the technical analysis of returned parts and parts.

For Yin (2001), a case study is: "an empirical investigation that analyzes a contemporary phenomenon within its real-life context, and when the boundaries between phenomenon and context are not clearly defined." According to Eisenhardt (1989) the case study can be used to provide a description; test a theory; or generate a new theory. Thus, the data obtained from the airbag recall operation were described and analyzed according to the chronological order of the events. The research model and hypotheses are then proposed, followed by the introduction of research methodology and the report of the data analysis results. This paper concludes with the discussion of theoretical and practical contributions, limitations, and avenues for future research.

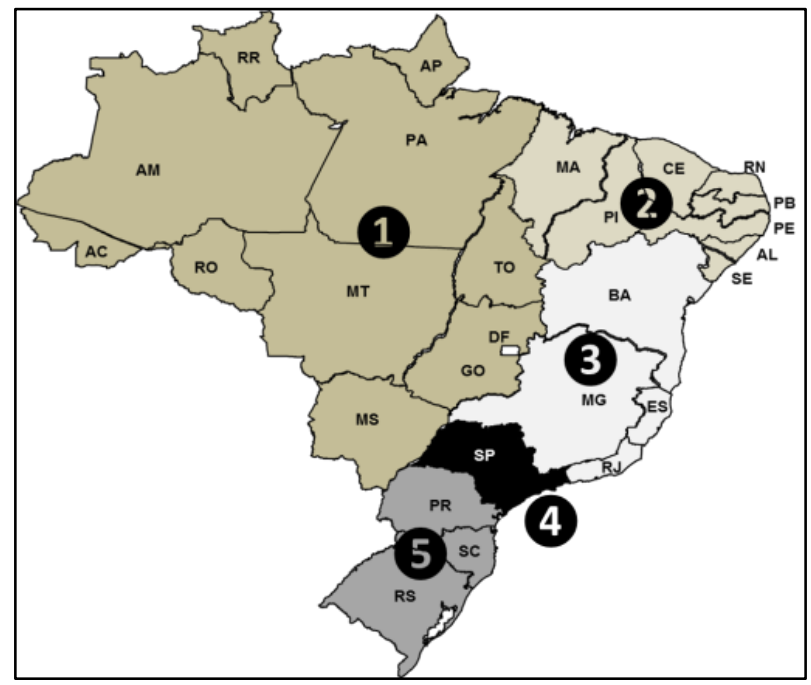

Figure 2. Distribution of Brazilian territory by service areas

\section{Discussion}

\section{Presentation and Analysis of Results}

\section{Air Bag Recall Process}

The "recall" process for any segment and for any company generates several necessary factors and actions are internal and / or external, to minimize the possible impacts to the final customers and company image.

Being an automobile company, due to the recent and numerous occurrences in a short time and by several brands, the negotiations of these actions of correction and prevention, has become one of the priorities in the form of accepting, conducting, acting and treating these 
proceedings until their conclusion.

It is noted that the "air bags" recall process caused by technical problems involved more than 30 million vehicles from several automakers in the world and specifically, about 3 million in Brazil.

Reverse logistics has a decisive and important role in the recall process where procedures and flows are designed exclusively to meet this specific demand.

The company in question has more than 200 points of service distributed throughout the great Brazilian territory, and is segmented according to Figure 3 below into 5 (five) large regions, according to the distribution and regions served by 5 loads.

Outbound logistics follows the full flow of the supply chain, that is, from the origin (factory) to the dealers (delivery points), through points of consolidation of cargo due to long distance and fractional distribution (low volume).

In fact, a "recall" process, where there is a whole commitment to image, end customer and understand the real root cause of the problem, reverse logistics becomes a differentiated process in the preservation of industrial operation.

Figure 3 presents a summary of the reverse logistic flow, from the collection of the volumes in the concessionaires to the final delivery of the same in the matrix of the automaker, for a careful analysis of the responsible technicians and subsequent shipment to the supplier.

Below is a descriptive summary of this logistical process:

- Carriers collect the volumes at each concessionaire in their respective region;

- The volumes go through several cargo consolidation centers until the arrival at the central hub of the carrier;
- Another carrier is in charge of collecting all central hubs of the carriers and consolidates the entire volume at its operational base;

- The cargo is then transported to the port of Santos (port of origin) to carry out all foreign trade procedures;

- The container is shipped in the maritime modal and after 35 consecutive days of transit, arrives at the port of destination (Asian ports);

- Once the documentary process has been completed in the port of origin, the container with the volumes is transported to the assembly plant;

- In the matrix, all the tests are performed to identify the possible root causes to solve the problem and later the volumes are delivered to the manufacturer for validation and technical analysis;

- $\quad$ Based on the final analyzes, the improvement of the product or production process to correct the errors is programmed.

To get an idea of the range and number of vehicles involved in one of the last recalls, below are some graphs that demonstrate this operation.

Chart 3 shows a total of 538,730 units involved in the air bag recall, which is distributed in 3 vehicle models, respectively "A", "B" and "C".

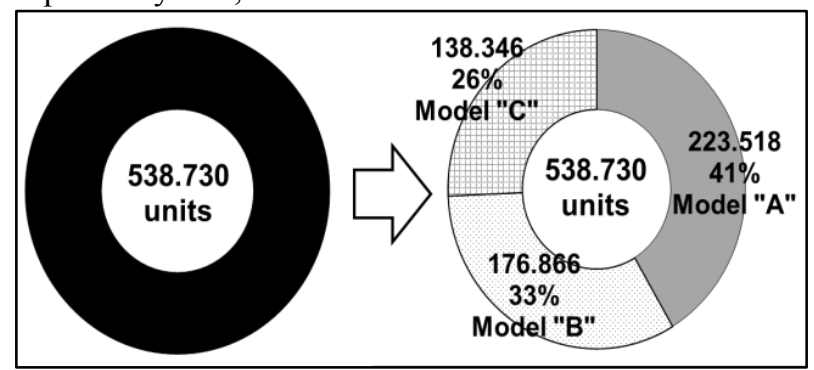

Source: By the authors

Chart 3. Total quantity and models included in the recall.

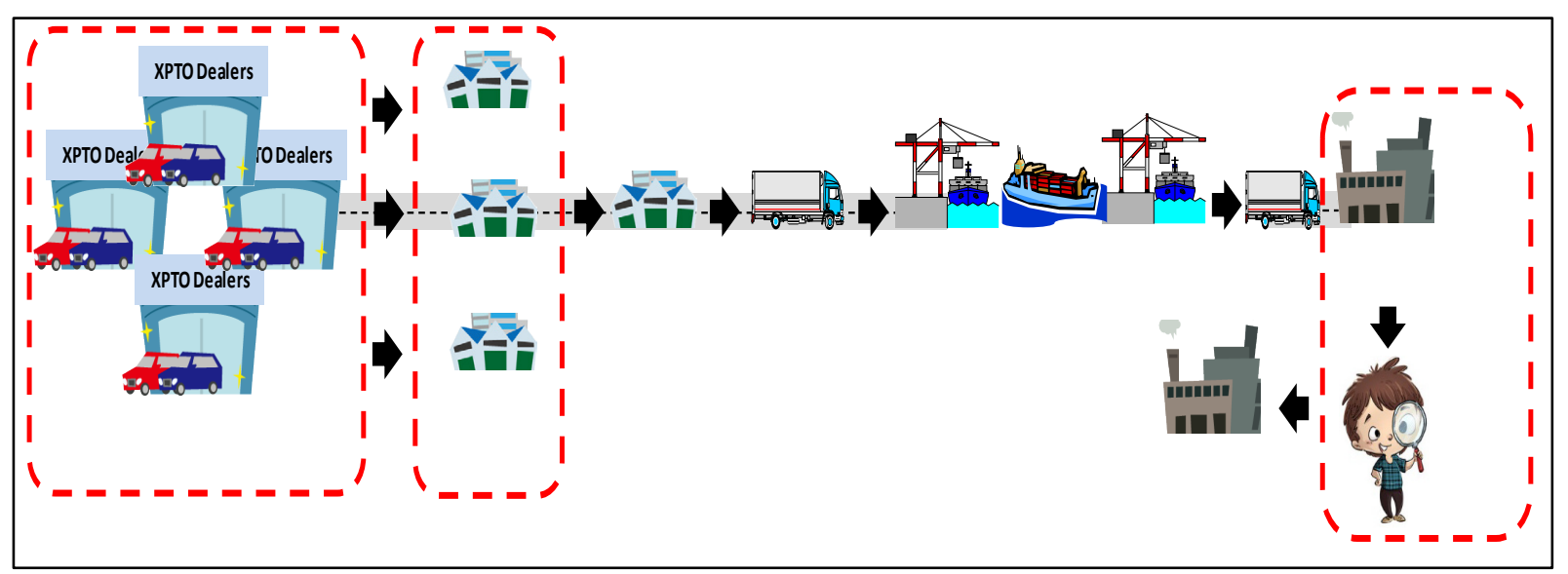

Source: By the XPTO company.

Figure 3. Reverse logistic flow in a recall process. 
Chart 4 shows the number of volumes transported in reverse logistics and the number of freights carried out in the period of 7 months (January to July 2017), with the total accumulated to date of 76,928 volumes transported in 7,351 freights.

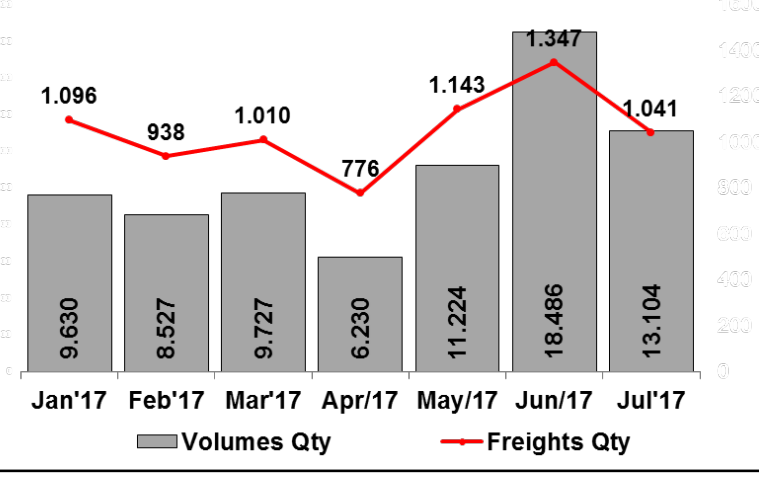

Source: By the authors.

Chart 4. Number of volumes transported $x$ quantity of freight carried out.

Chart 5 quantifies the 7,351 freight rates for the reverse logistics of 76,928 volumes, with an amount of $R$ $\$ 590,973$ spent to date and an average cost of $\mathrm{R} \$ 7.68$ per volume transported.

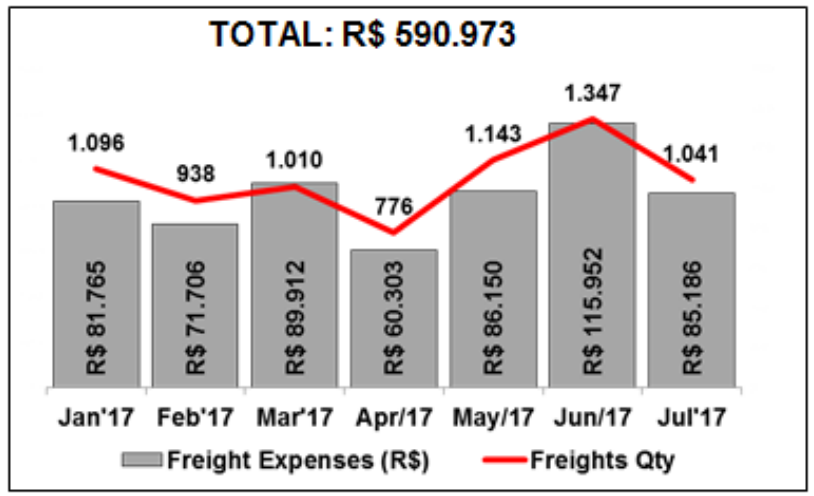

Source: By the authors.

Chart 5. Freight values paid $\mathrm{x}$ quantity of freight realized.

It is observed, however, that the management of the logistics is shared, that is, the subsidiary located in Brazil, is in charge of the move to the consolidation point and in the later links, the management is in charge of the Headquarter. However, freight costs are entirely absorbed by the parent.

It can be noticed that the XPTO assembler does not take any effort to collect all the defective parts involved in the recall and thus, to ensure that the customer service process is a priority, seeking its complete satisfaction.

This process constitutes the fundamental element of continuous improvement of the processes and the product because in the Headquarter the root cause of occurrence in the field is analyzed and evaluated. After its identification, it is established the procedure of including modifications and / or improvements in order to ensure the good functioning as well as the safety for the end user.

It is an innovative and unique initiative within the automotive segment, where the safety and reliability factor has a primary emphasis on corporate image at the global level.

\section{Conclusions / Final Considerations}

The research results show the importance of Reverse Logistics as a differentiating element in the implementation of continuous process and product improvement in business operations, as well as the sharing of responsibilities in the permanent search for image and customer satisfaction, as a differentiating factor in the segment of performance.

In fact, as shown in Chart 3, the cost of the operation is a factor of little relevance in the face of the qualitative gains in that it constitutes a precious asset that guarantees the continuity and the perenniality of the corporation.

Based on the described report, where reverse logistics plays a key role in the recall process, throughout the supply chain and in a structured and organized way, with a view to a rapid response to customers and consequent product improvement in itself, provide the continuity of sales of its products and the loyalty of its customers.

It is noted that the present research leads to important reflections in which the cost factor has implications in the company's results in the short term. However, over time the qualitative question is the element that ensures the image and fundamental institutional continuity that can differentiate in the long term. Being the eminently dynamic issue, it requires follow-up and studies involving new environments where it can be incorporated into future research.

\section{REFERENCES}

[1] ANFAVEA (2017a). Dados Estatísticos. Disponível em:< http://www.anfavea.com.br/estatisticas.html $>$. Data de acesso: 08 set. 2017.

[2] ANFAVEA (2017b). Anuário das Indústrias Automobilísticas Brasileiras. Disponível em:< http://www.anfavea.com.br/anuarios.html $>$. Data de acesso: 06 set. 2017.

[3] Berman, B., 1999. Planning for the inevitable product recall. Business Horizons 42 (March/April), 69-78.

[4] Blackburn, J.D., Guide Jr., V.D.R., Souza, G.C., Van Wassenhove, L.N., 2004. Reverse supply chains for commercial returns. California Management Review 46 (2), 6-22.

[5] CALDWELL, Bruce. www. informationweek. com/729/logistics. htm. April 
12, 2009

[6] Chen, Y., Ganesan, S., Liu, Y., 2009. Does a firm's product-recall strategy affect its financial value? An examination of strategic alternatives during product-harm crises. Journal of Marketing 73 (November), 214-226.

[7] Cohen, M. A., \& Whang, S. (1997). Competing in product and service: a product life-cycle model. Management science, 43(4), 535-545.

[8] Davidson, W.N., Worrell, D.L., 1992. The effect of product recall announcements on shareholder wealth. Strategic Management Journal 13 (6), 467-473.

[9] Dawar, N., Pillutla, M., 2000. The impact of product-harm crises on brand equity:the moderating role of consumer expectations. Journal of Marketing Research (May), 216226

[10] Eisenhardt, K. M. (1989). Building theories from case study research. Academy of management review, 14(4), 532-550.

[11] Guide Jr., V.D.R., Wassenhove, L.N.V., 2001. Managing product returns for remanufacturing. Production and Operations Management 10, 142-155.

[12] Hora, M., Bapuji, H., \& Roth, A. V. (2011). Safety hazard and time to recall: The role of recall strategy, product defect type, and supply chain player in the US toy industry. Journal of Operations Management, 29(7), 766-777.

[13] Jarrell, G., Peltzman, S., 1985. The impact of product recalls on the wealth of sellers. Journal of Political Economy 93, $512-536$.

[14] Jayaraman, V., Patterson, R.A., Rolland, E., 2003. The design of reverse distribution networks: models and solution procedures. European Journal of Operational Research 150 (2), 128-149.

[15] Johnson, M.E., 2001. Learning from toys: lessons in managing supply chain risk from the toy industry. California Management Review 43 (3), 106-126.

[16] LEITE, Paulo Roberto. Logística Reversa- Meio Ambiente e Competitividade. São Paulo: Editora Prentice Hall, 2003.

[17] Leite, P. R. (2009). Logística reversa: meio ambiente e competitividade. Pearson Prentice Hall.

[18] Petersen, J. A., \& Kumar, V. (2013, May). Are product returns a necessary evil? Antecedents and consequences. American Marketing Association.

[19] Prahinski, C., Kocabasoglu, C., 2006. Empirical research opportunities in reverse supply chains. Omega 34, 519-532.

[20] ROGERS, Dale S., TIBBEN.LEMBKE, Ronald S. Going Backwards: Reverse Logistics Trends and Practices. Reno, University of Nevada: 1999.

[21] Rupp, N.G., 2004. The attributes of a costly recall: evidence from the automotive industry. Review of Industrial Organization 25, 21-44.

[22] Shah, R., Ball, G. P., \& Netessine, S. (2016). Plant operations and product recalls in the automotive industry: An empirical investigation. Management Science.

[23] Smith, C.N., Thomas, R.J., Quelch, J.A., 1996. A strategic approach to managing product recall. Harvard Business Review 74, 102-112.

[24] Tang, C.S., 2008. Making products safe: process and challenges. International Commerce Review 8 (1), 48-55.

[25] Thirumalai, S., \& Sinha, K. K. (2011). Product recalls in the medical device industry: An empirical exploration of the sources and financial consequences. Management Science, 57(2), 376-392.

[26] Yin, R. K. (2001).Estudo de Caso-: Planejamento e Métodos. Bookman editora. 